\title{
PROBLEMS OF EDUCATIONAL WASTAGE IN PRIMARY LEVEL EDUCATION OF NEPAL: SOME SUGGESTIONS TO REDUCE IT
}

\author{
Bhupendra Hada*
}

\begin{abstract}
This paper presents the problems of wastage in education during 200608 at the primary level, in terms of repetition and dropout. The main objectives of this paper is to enumerate the reasons of repetition and dropout of students at primary school education, because they are the major barriers and stumbling block for the school education system of every country, and they also enhance to decrease internal efficiency of education system.

Promotion, repetition and dropout are the prominent indicators of internal efficiency. If the repetition and dropout rates are high, promotion rate will be low, and it indicates the low internal efficiency of the primary school education. There are many causal factors for educational wastage and they are explained in brief. Hence, the table and the figure available from DOE are used to analyze the sources of educational wastage in primary level education. The conclusions and recommendations are put forward for reducing educational wastage to minimum in the Nepalese context.
\end{abstract}

\section{INTRODUCTION}

More specifically, students' high repetition and high dropouts are the burden and they are the stumbling block for the nation. These are the loss of investment of government in the field of education. These losses harm to increase the internal efficiency of educational system in the country. Because of many reasons, children are bound to repeat in the same grade or dropout. This is thus, the more challenging is how to keep children engaged in study up to class five.

Different studies and research report have corroborated that to accomplish the study of primary level, it takes 9-12 years of schooling and the invest for a student, according to the data available in 1995/96, works out to Rs. 11510. From this, it can be concluded that the investment made by the government in the primary education seems not useful, productive, fruitful and meaningful (CERID 1999).

It is the collective accountability of all to achieve satisfactory output/results from the investment made in education. To accomplish this accountability, it is indispensable to be conscious. One of the major problems seen in the field of education is educational wastage. This problem is indeed seen at the primary level of education. Hence, educational wastage consists in dropouts, repeaters etc (Poudel 1994). The implication of such wastage reflects the poor internal efficiency of a school.

\footnotetext{
* Professor, Sanothimi Campus, Tribhuvan University, Bhaktapur, Nepal
} 


\section{WHAT IS EDUCATIONAL WASTAGE?}

Despite heavy investment in education, the outcome is not seen satisfactory as expected by the nation. The nation's investment on education, if wasted without satisfactory result / output of the target is said to be educational wastage/loss. In this vein, failure in examination from time to time, grade repetition and dropouts are considered to be the educational wastage. They are the huge educational wastage of nay nation, rich or poor. Our country Nepal is divided into four ecological regions, Mountain, Hill, Tarai and Mid-Tarai. The children of these ecological regions have different background, different culture and different circumstances. Children belong to different cultural and economic backgrounds come to school for their future career. Children are facing tremendous problems and the rural and remote areas of developing countries like Nepal cannot be separated from such problems.

Research reports and studies have shown the students' dropout and repetition in the same grade because of low family status, poor economic condition, lack of geographic and transport facilities. In Nepalese context, a large section of people are adamant, economically feeble and ignorant of value of education. They are not conscious about the meaning and value of education. In this scenario, parents hesitate to send their wards to school, because of their economic constraints, children are also aupair and they are in measurable condition. Parents also use their wards for their additional income and for the care of their younger siblings at the time of their absence at school. Consequently, number of students will be decreased. In order to focus the attention of students toward their study, teachers should have to play major role for the attention of students in their study. Teachers can motivate them toward their studies and encourage them to do homework. Thus, teachers' efficiency is a must to reduce the educational wastage in primary level, such as dropout and repetition. Following Table 1 and Figure 1 show the data of successful students (promoted to upper grade), repeaters and those who dropout at the primary level of three years in percentage.

\section{PARENTS' INFLUENTIAL ROLE IN EDUCATING THEIR CHILDREN}

Parents are regarded as the children's most influential teachers; because children spend more time at home than at school, and parents spend their valuable in children's learning.

Several studies support that the home is the child's first school; it influences as well as contributes greatly to a child in his/her studies. Hence, it is very important that congenial environment at home be created that can help a child to learn and can make him/her inquisitive (curious) enough to explore the world of learning. Likewise, a child can make more progress and that also in the right direction, if he/she gets all possible assistance in his/her study in home. Thus, there is a strong case for sensitizing the parents also to the need for assuming their role in supporting children's education at home (Malakar 1989-90).

Similarly, children are more likely to attend schools regularly while their parents provide the kind of support that is needed to be regular in schools. They have to encourage children to attend schools. Families, which are involved in their children's schooling, tend to support children with their homework (Hada 2004). 
Likewise, parents can help their children do their homework; talk with them about school work and take part in class teaching or assisting responsibilities (Lyons, Robbins and Smith 1982, cited in Bista 2003).

From above information, it is concluded that the parents' role in educating their children is a must and they can motivate and encourage their wards to do homework. Form this, educational wastage can be definitely reduced to minimum.

\section{OBJECTIVES}

The primary objective of the study is to present an analysis of the educational wastage at the primary level in the context of Nepal. More specifically, the study intends to accomplish the following objectives:

- $\quad$ To study the educational wastage during 2006 -08 in terms of repetition and dropout rate in the context of primary school education.

- $\quad$ To enumerate the causal factors for educational wastage at the primary level.

- $\quad$ To suggest conclusions and recommendations for reducing the educational wastage to minimum at the primary level in the Nepalese context.

\section{METHODOLOGY}

The researcher consulted the Department of Education (DOE), Sanothimi, Bhaktapur and requested the related personalities, such as Resource Person (RP), Section Officer (SO), School Supervisor (SO) and the Director of Department of Education (DDE) for supplying appropriate information concerning the sources of educational wastage in primary level education of Nepal. They co-operated with the researcher satisfactorily, and supplied the available data. They responded that the causes of the educational wastages in the primary level education are different and vary. They also supplied information about the causal factors for educational wastage of primary level in the country.

This study is therefore based on primary as well as secondary sources of information. Primary sources are drawn from face to face interview with above mentioned related persons. The secondary sources are based on information published from Department of Education (DOE) and Ministry of Education and Sports (MoES). The study has extensively used the data of School Level Educational Statistics of Nepal Consolidated Report 2008, which was published in June, 2009 annually published by the DOE. Sources are also taken from related books, magazines and journals. The Table and the Figure available from DOE are used to analyze the sources of educational wastage in primary level education. Thus, the study has used both quantitative and qualitative approach in order to analyze the objectives of the study.

\section{ANALYSIS}

The following Table 1 and Figure 1 present the percentage of promoters, repeaters, and dropouts at primary level from 2006-2008. The Table and Figure show the highest repetition rate in grade 1 , which reveals that still the most serious problems exist in grade 1 . It indicates that under age children are enrolled in grade 1 due to the lack of preparation of children for schooling and also the absence of Early Childhood Development (ECD)/Pre-primary classes (PPC). The Table and the Figure reveal that there is a significant co-relation between the 
repetition rate in grade 1 and the percentage of children in grade 1 with ECD/PPCs experiences. It also indicates the higher the grade the lower the repetition rate at primary level.

Similarly, the percentage of the dropout rate of the students' enrolled in a given grade in an academic year, in total; the average dropout rate in grade 1 was $20.9 \%$ in 2006, $16.1 \%$ in 2007 and $12.1 \%$ in the year 2008. Likewise, in total, the average dropout rate in grade 5 was $14.8 \%$ in 2006, $10.2 \%$ in 2007, and $9.2 \%$ in the academic year 2008. At the cursory glance, the internal efficiency of primary level corroborates the lowest promotion rates and highest repetition and dropout rates are prominent (well known) in grade 1. (See Table 1 and Figure 1)

Table 1. Promotion, repetition and dropout rates in 2006-08

In percentage

\begin{tabular}{|c|c|c|c|c|c|c|c|c|c|c|c|c|c|c|c|}
\hline & \multicolumn{3}{|c|}{ Grade 1} & \multicolumn{3}{|c|}{ Grade 2} & \multicolumn{3}{|c|}{ Grade 3} & \multicolumn{3}{|c|}{ Grade 4} & \multicolumn{3}{|c|}{ Grade 5} \\
\hline & ڤ્ & ڤ્̀ે & $\begin{array}{l}\infty \\
\stackrel{\sim}{े}\end{array}$ & \&્ণ & ڤ્ণิ & \&̊ & \&્ণ & ڤ્ণ & 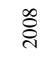 & ๕ั & ڤ્ণે & \&్లి & \&્ণ & ڤ્ণิ & \&̊ \\
\hline Promotion & 49.3 & 54.5 & 59.6 & 73.6 & 74.6 & 80.5 & 76.6 & 80.0 & 82.5 & 75.4 & 79.9 & 85.4 & 74.8 & 82.0 & 83.5 \\
\hline Repetition & 29.8 & 29.4 & 28.3 & 16.1 & 13.7 & 12.9 & 13.1 & 10.3 & 10.1 & 13.1 & 10.0 & 9.6 & 10.4 & 7.8 & 7.3 \\
\hline Dropout & 20.9 & 16.1 & 12.1 & 10.3 & 11.7 & 6.6 & 10.3 & 9.7 & 7.4 & 11.5 & 10.1 & 5.0 & 14.8 & 10.2 & 9.2 \\
\hline
\end{tabular}

Source: Flash 1 Report 2006-08.

In percentage

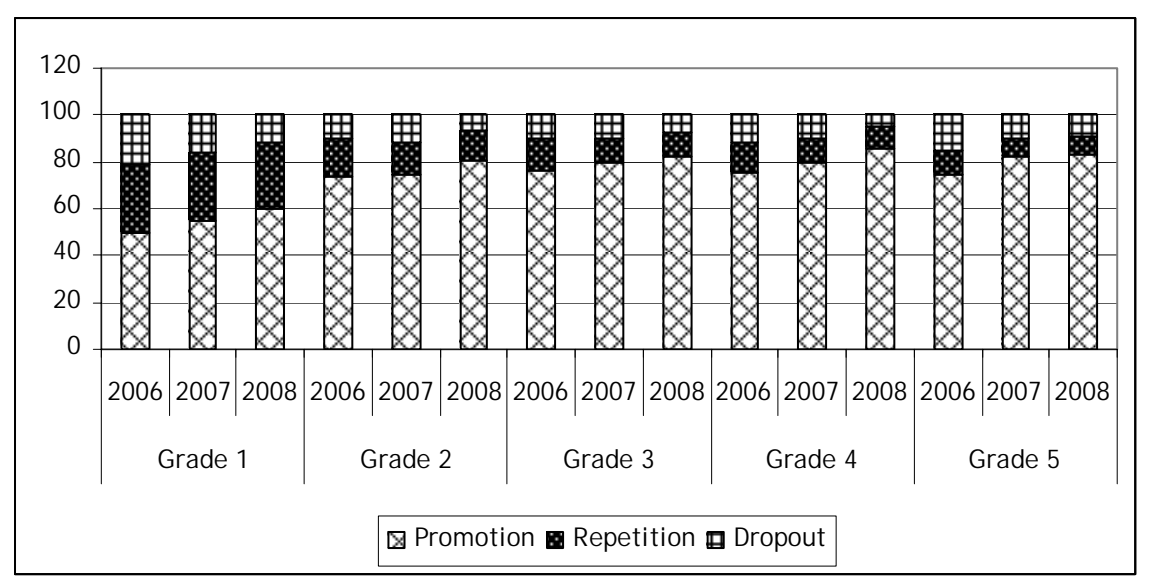

Source: Flash 1 Report 2006-08.

Figure 1. Promotion, repetition and dropout results in 2006-08.

The above interpretation adheres that the government including school management, stakeholders and local government agencies need to pay serious attention to reduce the high repetition and high dropout of the children at the primary level education, because high repetition and high dropout are the burden for the nation and they enhance to decrease the internal efficiency of school 
education. Thus, promotion, repetition and dropout are the prominent indicators of internal efficiency of school education.

\section{CAUSAL FACTORS FOR EDUCATIONAL WASTAGE}

National studies have pointed out many causes and factors, both internal and external, related to educational wastage. Non-enrolment, absenteeism, repetition, dropout, low achievement and insufficient utilization of resources for education are such factors contributing the educational wastage. China's definition of external factors include levels of socio-economic development, cultural traditions and values, geographical conditions, family background and socio-economic status, etc. Similarly, the internal factors include the philosophy of education, material conditions, pattern and distribution of schools, teaching force, teaching materials and methods, and so on.

Our countries have classified these causes into five groups of factors which are pupil related, parent/family related, teacher related, community and environment related. This can be illustrated by a case in which a child suffering from malnutrition, parents' negative attitude towards children' education, and poor quality of school instruction will have low learning achievement in the school (UNESCO 1990).

The wastage in this study also represents the high repetition and high dropout, parents' ignorance of value of education, unfavorable teaching learning environment, teachers failure to use the methods and technique learnt in the training are such factors that are closely related with educational wastage.

Similarly, low enrolment, majority of students lacking interest in learning and parents' poor attention toward their children's study are the other noticeable causal factors contributing to educational wastage in primary education system in Nepal.

Though it is said that education at public primary schools is free of cost, the parents are paying extra fees such as admission fee, examination fee, library fee maintenance fee etc to the school. The poor parents cannot afford all the fees and eventually their children dropout. Maintenance of enabling school environment has been directly linked to internal efficiency of the school. It has therefore remained a burning issue in the public primary schools.

Political stability is elusive in Nepal. Differences and vested interests of the political parties and the government have badly affected the well functioning of the education system in Nepal. The primary schools have not remained untouched by political turbulence. Strikes, Nepal close, valley close, black out, torch rallies and other various forms of disruptive demonstrations have negated the efficiency of teaching learning situation of the primary schools (Hada 2008).

Likewise, majority of children from poor families cannot afford to buy the basic materials they need for school and are in no case convinced that education will be of any use to them. A most discouraging aspect of the whole situation is that a large proportion of those children who manage to complete their primary schooling are not up to much in terms of learning achievement at the end of five years (UNICEF 1998). 
Problems of education for both boys and girls do not seem similar in Nepalese society. Cultural traditions and values, poor and the illiterate family background and poor socio-economic status may affect boys and girls differently. There are different ethnic groups with different language and cultural traditions of their own. Since the Ranas and Shahas, the aristocratic family regarded the son as the sole heir of the father and the controller of the family at the top of the family hierarchy, whereas the daughter only as subordinate to family subjected to kitchen work. For example, the son is sent to expensive private boarding schools or in the foreign country, whereas the daughter is sent to government school which is being operated more or less free of cost. But it is changing faster with the speed of time. At present, the arrangements are being made for equality between son and daughter. But in the remote sectors of our country, the problem have still remained unsolved because of the lack of understanding the value of education and poor socio-economic status together with traditional cultural beliefs.

\section{MAJOR FINDINGS}

From the above discussion of the study, following are the major findings drawn from the study:

1 In comparison to promotion rate, repetition and dropout rates are found higher in grade 1 .

2 Repetition rates are higher than dropout rate; it was $29.8 \%$ in grade 1 in 2006 and $28.3 \%$ in the same grade and some academic year, whereas dropout rate was $20.9 \%$ in grade 1 in 2006 and $12.1 \%$ in 2008 academic year.

3 Dropout rates are high in Grade 5; it was 14.8\% in 2006 and 9.2\% in 2008, whereas repetition rates were $10.4 \%$ in 2006 in the same grade and in the same academic year and $9.2 \%$ in the same grade and in the same academic year.

\section{CONCLUSIONS AND RECOMMENDATIONS}

Many problems affect the educational wastage in Nepal. In this perspective, poverty and the illiteracy are the major barriers/enemy of educational wastage. Hence, on the basis of major findings, following conclusions and recommendations are made for the study:

1 Home-school communication is a key to child's academic success. There must be free flow of information between school and parents with all the activities. School must provide information on their children's learning or behavior to all the parents. When the problems arise in school or classroom, teachers should also involve parents in solving these problems through discussions and interactions with the parents. For example, some schools bring out bulletins or newsletter to inform parents about school activities. These formal means of communication are conducive to motivate the parents to send their children at school.

Physical facilities affect the teaching learning situation in school. Primary schools are government oriented, because of lack of physical facilities, teaching learning situation will not be suitable, meaningful and fruitful. In order to reduce the wastage in education, school should well manage the physical facilities for the improvement of teaching learning 
environment. In this regard, the local resources, such as no cost and low cost instructional materials are also to be mobilized for effectiveness of learning environment.

3 The incidence of students' absence in class is high, because of geographic and transport difficulties. On the other hand, due to flooded rivers and streams, small children cannot go to school in the rainy season. The major problem of rural and remote areas of Nepal is the lack of roads. Hence, Nepal government should pay serious attention in this regard to reduce the educational wastage in primary level.

$4 \quad$ Illiteracy is one of the major problems of backward country like Nepal. Large majority of the parents of rural and remote areas of Nepal are illiterate and they are unknown about the value and necessity of education. In order to reduce the illiteracy rate, the government must sponsor many "Parents Awareness Programs" to motivate and encourage them. If parents are aware of illiteracy and know the value and necessity of education, they do not hesitate to send their children to school and definitely the education wastage will be reduced to minimum.

5 It is an absurdity in society, where the sons and daughters are looked from different angles. In our Nepalese society, daughters are regarded as a tool that must be handed to somebody in the future. Keeping in view, parents are not ready to pay a large amount sending their daughters at expensive schools. The daughters are sent to the kitchen and other household and domestic works, whereas the sons are sent to expensive boarding schools. The discrimination between son and daughter is also the major issue behind repetition and dropout.

\section{SUGGESTIONS FOR FURTHER RESEARCH}

From the findings of the study, a number of suggestions and recommendations can be put forward for undertaking further research in this area.

1 The present study shows the educational wastage in terms of repetition and dropout. The causal factors are different and vary. It depends on the family condition, status and their interest in education. The children should be encouraged to go to school and pay attention to their study. A further research is needed to find out the difficulties and unfavorable situation especially of those poor people who hardly maintain their life and unable to get educational facilities.

2 As the study revealed the problems and disabilities in learning regarding the poor people of low status, a further research should be undertaken to explore the factors affecting their learning, and put forward suggestions for their remedies.

3 The scope of investigation should be extended focusing the discrimination between son and daughter and its effect on primary school education.

4 A further research is needed to explore the factors affecting the children's health. Arrangement of mid-day meal, tiffin and distribution 
of various fooding materials encourage the children to come to school regularly and also contribute to improve their health. Such a provision should especially reach minority, Dalit children and girls in order to ensure their easy access to educational facilities.

\section{WORKS CITED}

American Psychological Association. 2006. Publication Manual of the American Psychological Association. (5 ${ }^{\text {th }}$ ed.). Washington D.C.

Bista, M. B. 2003. Parental involvement in education. Siksa 2004 Annual Education Journal. Curriculum Development Centre, Sanothimi, Bhaktapur. Pages 146.

CERID. 1987. An Enquiry into the Causes of Primary School Dropouts in Rural Nepal (A study report). Kathmandu.

CERID. 1988. Causes of Wastage in Primary Education. Pages 33-38 in Wastage of Primary Education in Nepal. Kathmandu.

CERID. 1999. Educational Wastage. Pages 73-89 in Supervision in Basic and Primary Education. Kathmandu.

DOE 2009. Internal efficiency. School Level Educational Statistics of Nepal Consolidated Report, 2008. Bhaktapur. Pages 37.

Hada, B. 2000. Educational Loss. Pages 37-41 in Education and Development: Research Center for Educational Innovation and Development (CERID). Kathmandu.

Hada, B. 2004.Parental involvement at the primary level education. Siksa 2004 Annual Journal. 153, Curriculum Development Center, Bhaktapur.

Hada, B. 2008. Political interference. Internal efficiency of primary education system in Nepal. Ph.D. Dissertation, Kathmandu. Pages 180.

Malakar, Sunita. 1989-90. Parental involvement in education of children. Pages 143-44 in Education and development. Research Center for Educational Innovation and Development (CERID), Kathmandu.

Poudel, P. R. 1997. Educational wastage (in Nepali). Pages 12-13 in Sandesh Magazine, Resource Center Development Unit. Sanothimi, Bhaktapur.

Sidhu, K. B. 1995. Research needs in education. Pages 34-35 in Methodology of Research in Education. Sterling Publishers Pvt. Ltd., New Delhi.

UNESCO. 1990. Reducing wastage and increasing efficiency in education (Draft synthesis report). Pages 22-23 in Regional Study of Wastage in Education. National Institute for Educational Research (NIER), Tokyo, Japan.

UNICEF, ROSA. 1998. The challenges of achieving for all. Quality and Innovation in Primary Education. Primary and Mass Education Division (Regional Organization for South Asia), Kathmandu, Pages 5. 